\title{
Case of Cronkhite Canada Syndrome - A Non-Inherited Gastrointestinal Polyposis Syndrome
}

\author{
Arun Solanki , Rajesh Bhurkunde ${ }^{2}$
}

${ }^{1}$ Senior Resident, Department of General Medicine, TNMC \& BYL Nair Hospital, Mumbai, Maharashtra, India. ${ }^{2}$ Assistant Professor, Department of General Medicine, TNMC \& BYL Nair Hospital, Mumbai, Maharashtra, India.

\section{PRESENTATION OF CASE}

A 56-year-old male presented with complaints of non-bloody watery diarrhoea, weight loss since past one year and pigmentation over face and distal extremities since eight months. Patient gave history of loose stools, watery, small in quantity, occasionally mixed with blood but not accompanied with mucosa or fat and with frequency of around 10 episodes per day, sometimes even at night. Loose stools were not related to food consumption, mental stress or any drugs. There was no history of fever, nausea, abdominal pain, vomiting. No h/o oral ulcer/ pigmentation. Patient was operated for cataract ten years back. He was non hypertensive and non-diabetic. No past history of psychiatric illness. No similar complaints in any other family member. Consumes mix diet, denies addictions. On physical examination, vitals were within normal limits, he had hyperpigmentation over face, both hands involving both palms and both legs involving soles (Figure- 1,2,3) alopecia and dystrophic nail changes (Figure-4). No pigmentation was noted in the oral cavity. No signs of vitamin deficiency were seen. His abdomen was soft with no tenderness and it was nondistended with no palpable organomegaly. Rest of the physical examination was not contributory. The laboratory parameters including complete blood counts, renal and liver function tests, serum electrolytes were within normal limits except hypocalcaemia ( $8 \mathrm{mg} / \mathrm{dl}$; normal range: $8.6-10.5 \mathrm{mg} / \mathrm{dl}$ ) hypoalbuminemia $(2.8 \mathrm{~g} / \mathrm{dl}$; normal: $3.5-5 \mathrm{~g} / \mathrm{dl}$ ). To further investigate his condition, special tests were done like ESR: 30; HIV/HBsAg/Anti HCV: Negative; FT3, FT4, TSH: Normal; Serum 8 AM cortisol- normal, Sr. Vit. B12 level: normal, Sr. ANA: negative, USG abdomen: normal. Stool was negative for occult blood. Patient underwent an upper GI endoscopy which was also normal. On colonoscopy, there were multiple polypoidal lesions extending from distal transverse colon till rectum (Figure-5).

\section{DIFFERENTIAL DIAGNOSIS}

1. Inflammatory diarrhoea

2. Malabsorption syndrome

3. Addison's disease

4. Colonic carcinoma

5. Colonic polyps

\begin{tabular}{|c|c|c|c|c|c|}
\hline & $\begin{array}{c}\text { Cronkhite } \\
\text { Canada } \\
\text { Syndrome }\end{array}$ & Peutz-Jeghers Syndrome & Juvenile Polyposis & $\begin{array}{c}\text { Cowden } \\
\text { Syndrome }\end{array}$ & $\begin{array}{c}\text { Hereditary } \\
\text { Mixed } \\
\text { Polyposis }\end{array}$ \\
\hline Polyps & $\begin{array}{c}\text { Multiple and } \\
\text { sessile }\end{array}$ & Multiple & Multiple polypoidal & Multiple & $1-15$ polyps \\
\hline $\begin{array}{c}\text { Ectodermal } \\
\text { findings }\end{array}$ & Present & Present & Absent & Present & Absent \\
\hline Dysplasia & Absent & $\begin{array}{c}\text { Displaced mucosa with pseudo- } \\
\text { invasion of underlying } \\
\text { muscularis propria }\end{array}$ & Present & None & Present \\
\hline Inheritance & Non- familial & Autosomal dominant & $\begin{array}{c}\text { Autosomal dominant } \\
\text { (75\% new mutations) }\end{array}$ & $\begin{array}{c}\text { Autosomal } \\
\text { dominant }\end{array}$ & $\begin{array}{c}\text { Autosomal } \\
\text { dominant }\end{array}$ \\
\hline $\begin{array}{c}\text { Associated } \\
\text { features }\end{array}$ & $\begin{array}{c}\text { Skin hyper- } \\
\text { pigmentation } \\
\text { only }\end{array}$ & $\begin{array}{c}\text { Mucocutaneous hyper- } \\
\text { pigmentation }\end{array}$ & $\begin{array}{c}\text { Breast } \\
\text { hamartoma and } \\
\text { thyroid carcinoma }\end{array}$ & \\
\hline \multicolumn{7}{|c|}{ Table 1. Differential Diagnosis for Gastrointestinal Polyps } \\
\hline
\end{tabular}

Corresponding Author: Dr. Arun Solanki,

1D, 1305, Vighnaharta Apartment, Rambhau Bhogle Marg,

Cotton Green, Mumbai-400033,

Maharashtra, India.

E-mail:aurosolanki@gmail.com

DOI: 10.14260/jemds/2019/662

Financial or Other Competing Interests: None.

How to Cite This Article:

Solanki A, Bhurkunde R. Case of Cronkhite Canada syndrome- a non-inherited gastrointestinal polyposis syndrome. J. Evolution Med. Dent. Sci. 2019;8(40):30463049, DOI: 10.14260/jemds/2019/662

Submission 05-08-2019,

Peer Review 17-09-2019,

Acceptance 25-09-2019,

Published 07-10-2019. 


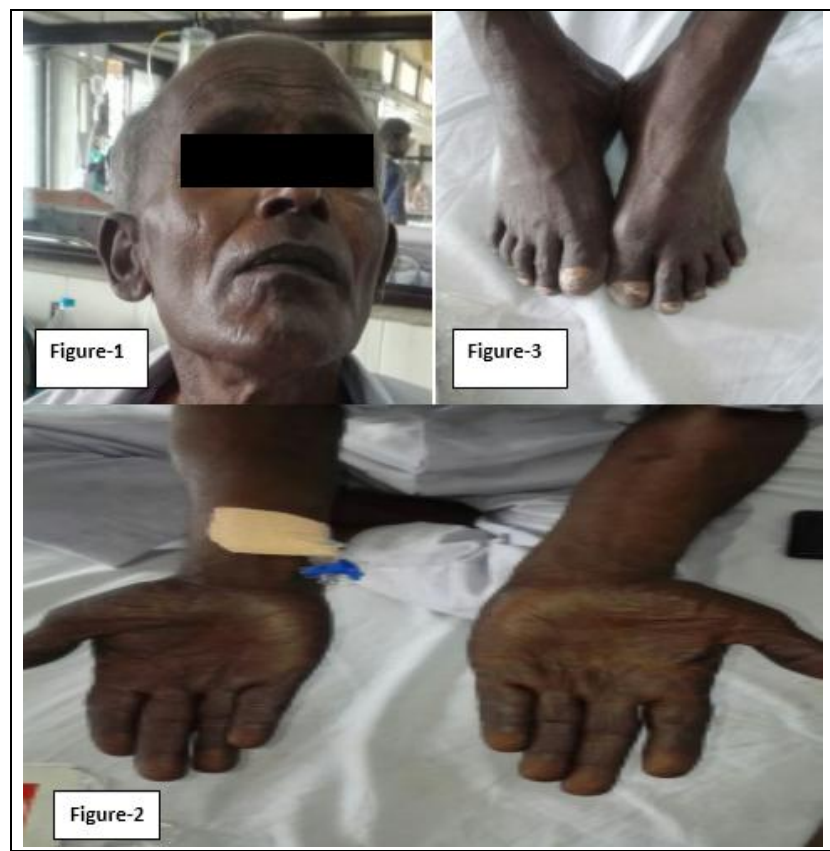

Figure 1, 2, 3. Showing Hyperpigmentation in Face, Hands and Feet including Palms
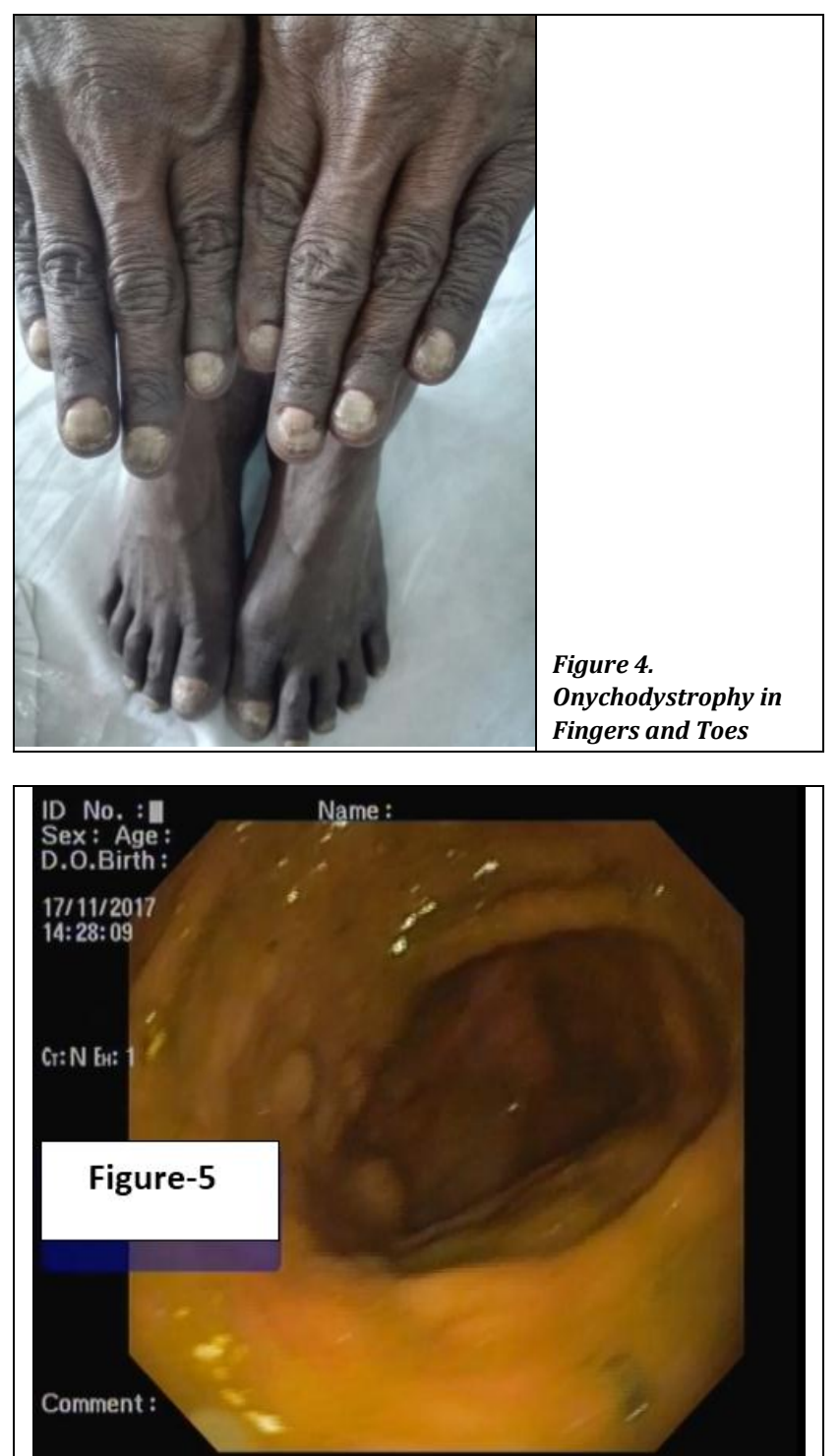

Figure 5. Multiple Sessile Polypoidal Lesions in Colon

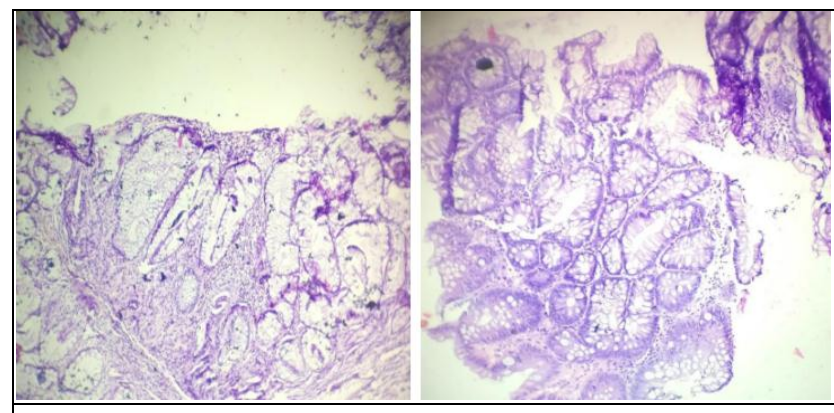

Figure 6. Histopathology of Biopsy of Colonic Polyp Shows Hyperplastic Polyp without Evidence of Dysplasia or Metaplasia
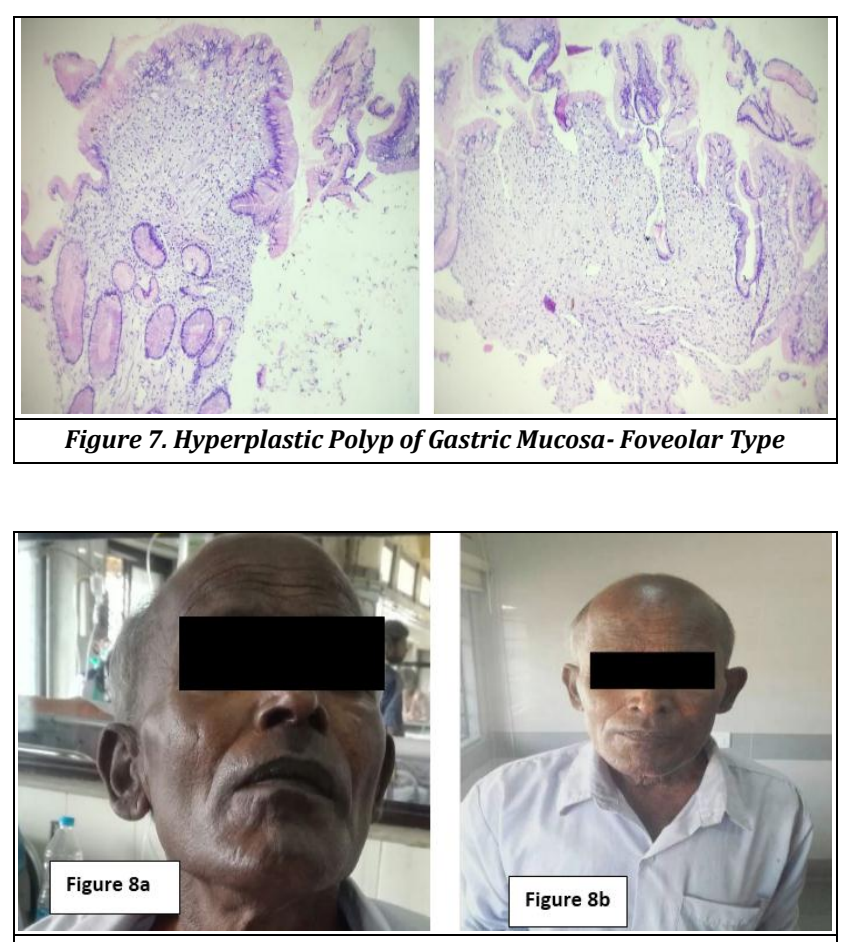

Figure $8 a$ \& 8 b. Shows Pigmentation Over Face Before and After the Initiation of Steroids

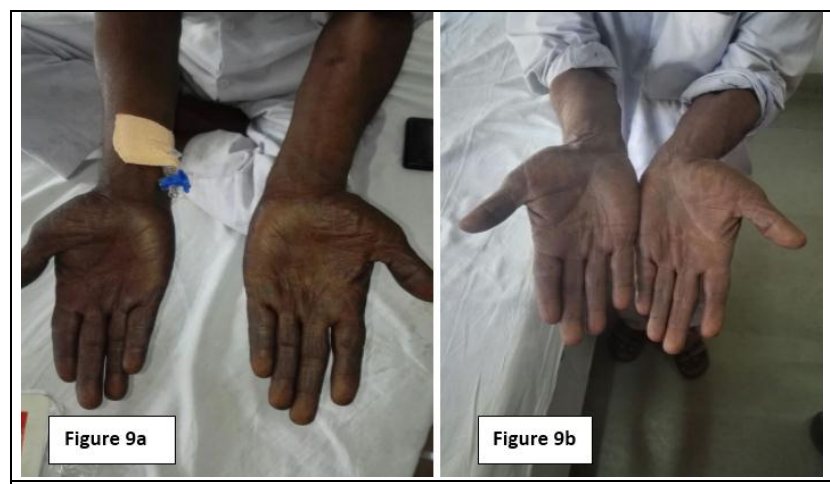

Figure 9a \& 9b. Shows Pigmentation Over Hands Including Palms Before and After the Initiation of Steroids

\section{PATHOLOGICAL DISCUSSION}

Histopathological examination of biopsies obtained from those polyps were suggestive of hyperplastic polyp without evidence of dysplasia or metaplasia (Figure-6, 7). So, on the basis of clinical features supported with colonoscopic and 
histopathological findings, the final diagnosis of this patient was Cronkhite Canada Syndrome.

\section{DISCUSSION OF MANAGEMENT}

Patient was given treatment with oral prednisolone which was started at $1 \mathrm{mg} / \mathrm{kg}$ with plan for gradual taper based on response. Pantoprazole (40 mg once daily) and Loperamide (2 $\mathrm{mg}$ ) were started which decreased the stool frequency and pigmentation over the body (Figure-8, 9). He was asked to continue the pantoprazole and prednisolone for at least one year. Patient was discharged in stable condition and was advised to undergo regular annual endoscopic study.

\section{DISCUSSION}

CCS is a condition which is based on features of malabsorption in the setting of characteristic clinical, endoscopic, radiologic, and histologic findings. First clinical description of CCS was first made in 1955 by Cronkhite and Canada.[1] However, Jarnum and Jensen were the first to establish the term CCS in 1966. [2] CCS is very rare with an estimated incidence of about one per million according to the largest study on CCS which included a total of 110 patients. Most frequently affected individuals are of Asian or European descent and majority of the cases are reported from Japan. ${ }^{[3]}$

CCS can affect in all ethnic groups with a slight male predominance is noted in almost all studies. It is mostly sporadic as there is no strong evidence to suggest a familial predisposition. Aetiology most probably involved in pathogenesis is autoimmune because there is increased immunoglobulin (Ig) G4 mononuclear cell staining in CCS polyps. ${ }^{[4]}$ Various other autoimmune conditions such as hypothyroidism, scleroderma, rheumatoid arthritis and systemic lupus erythematosus are also found in increased frequency with CCS patients. Some patients were also found to have elevated levels of Antinuclear antibody (ANA) and IgG4.[5]

Onset of symptoms usually starts in fifth to sixth decade. The most common initial symptoms are diarrhoea and dysgeusia and the dermatologic triad which includes hyperpigmentation, alopecia and onychodystrophy often occurring later. Malabsorption occurs due to the gastrointestinal polyposis which induced these ectodermal changes.[6] The index patient was a 56-year-old male presented with these characteristic manifestations. Yun et al., reported a 72-year-old male patient, a case of CCS who presented with diarrhoea and weight loss along with hyperpigmentation, nail dystrophy, and alopecia.[7] Kao et al., reported a case of a 39-year-old Filipino woman who initially presented with loose stools but later also developed hyperpigmentation of her palms and soles along with significant amount of hair loss. ${ }^{[8]}$ Seshadri et al., reported yet another case of CCS in a 78-year-old Chinese man who presented with altered sense for six months, diarrhoea and weight loss and was also found to alopecia, hyperpigmentation of both hands and atrophic nail changes.[6]

CCS patients can develop polyps which involves majority of the gastrointestinal tract except in the oesophagus and are usually hamartomas which are non-neoplastic. These polyps are similar in pathology to that of juvenile or inflammatory type polyps but also have marked eosinophilic inflammation and stromal oedema. ${ }^{[9]}$ CCS patients may occasionally develop adenomatous polyps which further leads to colorectal cancer.[10] Sigmoid colon and rectum are the most common sites for malignancy.[11]

Anaemia, gastrointestinal bleeding, malabsorption, and rectal prolapse are common complications.[5] The index patient had gastrointestinal bleeding with anaemia. Some uncommon complications and concomitant diseases which have been noted includes recurrent severe acute pancreatitis, myelodysplastic syndrome, cecal intussusception, portal thrombosis, and membranous glomerulonephritis.[12-15]

Aggressive screening in CCS patients is required as there is significant risk of colorectal cancer (Around 25\%) but due to the rarity of the disease, optimal screening protocols are still not developed, although annual endoscopic surveillance has been widely practiced.[9]

Differential diagnosis includes juvenile polyposis, Cowden disease, Peutz-Jeghers syndrome and familial adenomatous polyposis. CCS is differentiated from other hamartomatous polyposis syndromes by its widespread polyp distribution throughout the gastrointestinal tract but sparing of the oesophagus.[6] Typical clinico-pathologic and endoscopic features supported with extra-intestinal manifestations of CCS help in its distinction. [5]

CCS therapies have included proton pump inhibitors for suppression of acid and corticosteroids for treatment of protein-losing enteropathy, weight loss, and diarrhoea; nonsteroidal anti-inflammatory drugs for suppression of polyps.[17] Symptomatic management involving combination therapy based on nutritional support including Total parenteral nutrition and corticosteroids appears to decrease the symptoms. The total duration of treatment period is also unknown; although recommendations range from 6 to 12 months of combined therapy. [5,17] The index patient was treated with loperamide, pantoprazole and prednisone which provided him significant relief.

\section{REFERENCES}

[1] Cronkhite LW Jr, Canada WJ. Generalized gastrointestinal polyposis: an unusual syndrome of polyposis, pigmentation, alopecia and onychotrophia. N Engl J Med 1955;252(24):1011-5.

[2] Jarnum S, Jensen H. Diffuse gastrointestinal polyposis with ectodermal changes. A case with severe malabsorption and enteric loss of plasma proteins and electrolytes. Gastroenterology 1966;50(1):107-18.

[3] Goto A. Cronkhite-Canada syndrome: epidemiological study of 110 cases reported in Japan. Nippon Geka Hokan 1995;64(1):3-14.

[4] Sweetser S, Ahlquist DA, Osborn NK, et al. Clinicopathologic features and treatment outcomes in Cronkhite-Canada syndrome: support for autoimmunity. Dig Dis Sci 2012;57(2):496-502.

[5] Sweetser S, Boardman LA. Cronkhite-Canada syndrome: an acquired condition of gastrointestinal polyposis and 
dermatologic abnormalities. Gastroenterology and Hepatology 2012;8(3):201-3.

[6] Seshadri D, Karagiorgos N, Hyser MJ. A case of CronkhiteCanada syndrome and a review of gastrointestinal polyposis syndromes. Gastroenterol Hepatol (NY) 2012;8(3):197-201.

[7] Yun SH, Cho JW, Kim JW, et al. Cronkhite-Canada syndrome associated with serrated adenoma and malignant polyp: a case report and literature review of 13 Cronkhite-Canada syndrome cases in Korea. Clin Endosc 2013;46(3):301-5.

[8] Kao KT, Patel JK, Pampati V. Cronkhite-Canada syndrome: a case report and review of literature. Article ID 619378, Gastroenterol Res Pract 2009;2009: p. 4.

[9] Nakamura M, Kobashikawa K, Tamura J, et al. CronkhiteCanada syndrome. Intern Med 2009;48(17):1561-2.

[10] Malhotra R, Sheffield A. Cronkhite-Canada syndrome associated with colon carcinoma and adenomatous changes in C-C polyps. Am J Gastroenterol 1988;83 (7):772-6.

[11] Nagata J, Kijima H, Hasumi K, et al. Adenocarcinoma and multiple adenomas of the large intestine, associated with Cronkhite-Canada syndrome. Dig Liver Dis 2003; 35(6):434-8.
[12] Yasuda T, Ueda T, Matsumoto I, et al. Cronkhite- Canada syndrome presenting as recurrent severe acute pancreatitis. Gastrointest Endosc 2008;67(3):570-2.

[13] Suzuki R, Irisawa A, Hikichi T, et al. Cronkhite-Canada syndrome associated with myelodysplastic syndrome. World J Gastroenterol 2009;15(46):5871-4.

[14] Ishikawa E, Kudo M, Minami Y, et al. Cecal intussusception in an adult with Cronkhite-Canada syndrome relieved by colonoscopy. Intern Med 2010;49(12):1123-6.

[15] Takeuchi Y, Yoshikawa M, Tsukamoto N, et al. CronkhiteCanada syndrome with colon cancer, portal thrombosis, high titer of antinuclear antibodies and membranous glomerulonephritis. J Gastroenterol 2003;38(8):791-5.

[16] Burke AP, Sobin LH. The pathology of Cronkhite-Canada polyps. A comparison to juvenile polyposis. Am J Surg Pathol 1989;13(11):940-6.

[17] Ward EM, Wolfsen HC. Pharmacological management of Cronkhite-Canada syndrome. Expert Opin Pharmacother 2003; 4(3):385-9. 